\title{
Management Control System Design: Conditional Inter-dependencies between Behavioral Constraints, Incentives and Employee Selection
}

Leonard Strauß ${ }^{1}$

\begin{abstract}
My research contributes to the understanding of management control system design. Despite ongoing relevance and over 30 years of research there is still a limited understanding about the interdependence of management control. In this paper I analyze the interdependencies of behavioral constraints, incentives and employee selection under differing degrees of task uncertainty and output immeasurability. I find that in situations characterized by low task uncertainty and low output immeasurability employee selection and behavioral constraints act as substitutes. In a low task uncertainty/high output immeasurability context behavioral constraints and employee selection appear to act as substitutes. In a high task uncertainty/low output immeasurability setting there appear to be no significant interdependence effects between behavioral constraints, incentives and employee selection. Lastly, given a high task uncertainty/high output immeasurability background I find that incentives and employee selection act as complements and employee selection and behavioral constraints are substitutes. In addition to contextual factors managers have to take these interdependencies into account when designing optimal management control systems in order to achieve both external fit and internal consistency.
\end{abstract}

\section{Introduction}

Agency research in managerial accounting assumes that an optimal employment relationship is prevented, because the principal-agent relationship in organizations is characterized by information asymmetry and the agent's work and risk aversion (Baiman, 1990). In relation to management control (MC) this research focusses on the agency conflict within the organization, hence between managers and other employees, rather than between the owners and the managers of a company. The conflict limits the ability of the organization to achieve its objectives, since employees are expected to act in their self-interest rather than in the interest of the organization (Baiman, 1990). In order to mitigate this conflict and ensure the effective

\footnotetext{
${ }^{1}$ Leonard Strauß received a bachelor degree in International Business at Maastricht University in 2014. He will continue his studies with a Master in International Business (CEMS MiM) at the Stockholm School of Economics in 2015.
} 


\section{Management control system design}

achievement of objectives, management control practices are put in place. Management control is defined as "the process by which managers influence other members of the organization to implement the organization's strategies" (Anthony, 1988, p. 10). Therefore the core task of management control is taking care that employees behave consistently with the organization's overall objectives. This involves ensuring that employees (1) have an understanding of which actions they are required to take, (2) actually undertake the required actions and lastly (3) are capable of executing the required actions (Merchant \& Van der Stede, 2007, p. 7).

Most contingency-based research has followed the more conventional view of management control practices as passive tools for decision-support (Chenhall, 2003). When looking at the above defined tasks of management control, it becomes clear that while decisionsupport tools might enhance employees understanding of the required actions and increase their capability to undertake the right actions they do not cover the full responsibility of management control. Therefore, relying on what Anthony (1988) and Merchant and Van der Stede (2007) define as management control, I am following the broader approach of viewing management control practices as control tools, which include decision-support tools but encompass a wider selection figure 1. Management control
practices/mechanisms

Management control system

Management control systems package

Personnel controls such as selection and training, cultural controls, behavioral constraints, incentives, performance evaluations, budgets etc.

(Chenhall, 2003)

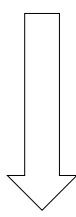

Collection of interrelated management control practices for process A (e.g. production)

(Grabner \& Moers, 2013)

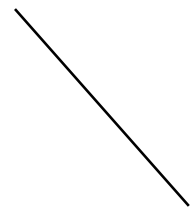

Collection of management control systems for the organization Includes all management control practices both interrelated and independent of each other (Grabner \& Moers, 2013)

Figure 1: Definitions and relationships of management control practices/mechanisms, management control system and management control systems package 


\section{Management control system design}

The rising focus on human resources as a source of competitive advantage (Wright, Dunford, \& Snell, 2001) corroborates the enduring importance of effective management control in its function to leverage these resources. Overcoming the preconception of being an obstacle to innovation, contemporary research increasingly interprets control as a key element of the dynamic organization (Davila, Foster, \& Oyon, 2009). Despite ongoing relevance and over 30 years of research there is still a limited understanding about the interdependence of management control practices other than accounting-based controls in different contexts (Malmi \& Brown, 2008). The need for empirical work on this issue in order to understand how management control systems operate (Abernethy \& Brownell, 1997) has remained unfulfilled.

The reason for the negligence of interdependencies between control practices in management accounting research is attributed to a number of challenges that come with this issue. Firstly, as mentioned above, there are different views on the scope of management control. A second challenge is that management control systems are often very complex and multiple management control systems within the organization form an overall management control systems package (Malmi \& Brown, 2008). The complexity issue is tackled by using a dataset that specifically examines the management control practices of the core process in medium-sized companies as explained in section III. A third challenge is that the term management control system and management control systems package are not used consistently within the management accounting research literature. I follow the definitions proposed by Grabner and Moers (2013, p. 408) who define management control system as a designed collection of management control practices that "are interdependent and the design choices take these interdependencies into account" and management control systems package as "the complete set of control practices in place, regardless of whether the management control practices are interdependent and/or the design choices take interdependencies into account". Figure 1 illustrates the different definitions and their relationships used in this paper. It is important to note that within the management accounting literature it is also common to use the term management control system for what I define as management control practices or mechanisms and the term management control package for what I define as management control system.

In this paper I analyze the interdependencies of behavioral constraints, incentives and employee selection under differing degrees of task uncertainty and output immeasurability. I chose to examine the given controls under these contextual variables because of their mutual representation in the most prevalent control frameworks which are discussed in section 2 . Since the examined controls exist at least to some degree in nearly every organization I aim at 


\section{Management control system design}

providing findings that are relevant to a large number of both researchers and practitioners. Section 3 explains the characteristics of the data that is examined and how the variables are measured. Section 4 is dedicated to the analysis of the conditional interdependencies. Section 5 forms the conclusion of the results of this paper. Section 6 reveals the limitations of my findings and proposes implications for future reseach.

\section{Theory and Hypotheses Development}

\subsection{Theories}

The three most prevalent control frameworks in the management accounting literature are Ouchi's (1979) market-bureaucratic-clan control framework, Simons' (2000) input-process-output control framework, and Merchant and Van der Stede's (2007) personnel/cultural-action-result control framework. Especially Simons' (2000) and Merchant and Van der Stede's (2007) frameworks show a large degree of congruence in the way they differentiate between control types. When determining on which type of control to rely on under different contextual conditions, Ouchi (1979) distinguishes between clan, behavior and output controls (behavior and output control both being part of bureaucratic control), which is consistent with the other two frameworks. Although the frameworks are not absolutely supposable because of scope differences, the congruence of the frameworks becomes apparent when looking at what kind of control procedures fall into the three respective categories. Employee selection falls in the input/personnel/cultural/clan control definition, behavioral constraints are found in process/action/behavior control, and incentives are a part of output/result control (Merchant \& Van der Stede, 2007; Ouchi, 1979; Simons, 2000). To be consistent I am labeling the control types personnel/cultural control, behavior control, and result control for the remainder of this paper. For the testing of the interdependencies between these control types I selected employee selection as a management control practice for personnel/cultural control, behavioral constraints for behavior control and incentives for result control.

In this paper I am specifically examining the interdependencies between behavioral constraints, incentives and employee selection. Behavioral constraints are aimed at preventing employees to engage in behavior that is not desirable by the organization. This includes not granting employees access to information or decisions that are outside the scope of their responsibilities, for example through segregation of duties (Merchant \& Van der Stede, 2007). In practice this is characterized by low decision autonomy on the side of the employee. I use the term incentives in this paper to describe the degree to which an organization rewards its 


\section{Management control system design}

employees for performance in monetary terms. Terms used in other research such as performance-based-pay or pay-for-performance can be understood as equivalent. As employee selection I define the importance placed on the recruitment process and the amount of resources (time and money) which is invested in this process. All three management control practices exist to some degree in most organizations. When I talk about relying on a particular practice this does not imply nonexistence of the other, but rather tighter behavioral constraints, incentives playing a larger role in the remuneration package or larger investment of resources into the recruitment process.

Since the composition of management control systems depends on a multitude of contextual conditions (Chenhall, 2003), I examine the interdependencies of the above mentioned control practices in different settings. According to Simons (2000, p. 63) the choice of control practice is determined by four criteria, namely (1) the technical feasibility of monitoring and measuring behaviors or results, (2) the understanding of the relationship between behaviors and results, (3) costs, and (4) the desired level of innovation. Criterion one includes characteristics of both task uncertainty (the inability to measure and monitor behaviors) and output immeasurability (the inability to measure and monitor results). Criterion two is also a part of task uncertainty. Similarly the criteria Ouchi (1979, p. 843) looks at when determining which control procedure to rely on are (1) knowledge of the transformation process and (2) the ability to measure outputs, which again characterize task uncertainty and output immeasurability. Finally Merchant and Van der Stede (2007) identify the degree to which knowledge about the desirable actions exist as a key determinant of management control system design. Given their consistent appearance in all three control frameworks I chose task uncertainty and output immeasurability as contextual conditions under which I examine the interdependencies of behavioral constraints, incentives and employee selection. As task uncertainty I define the degree to which a knowledge about the desirable behavior exists and the degree to which this behavior can be monitored. A process with a low task uncertainty is the storage of goods while a process with high task uncertainty is the research and development process. As output immeasurability I define the degree to which knowledge about the optimal result exists and the ability to measure results. A process with low output immeasurability is the contruction process while a process with high output immeasurability is a consultancy project.

The following discussion of complementarity theory in relation to management control systems is adapted from Grabner and Moers (2013). Assuming that managers select management control practices based on the contextual conditions and the internal consistency of these practices, the net value of a control practice is determined by the marginal benefit this 


\section{Management control system design}

management control mechanism adds to the management control system minus the cost of its adoption. MC practices are interdependent if marginal value of an individual management control practice to a MC system is increased or decreased by the existence of other management control practices in the MC system. Interdependency can take one of two forms; either the value of one MC practice decreases by the simultaneous existence of another MC practice in the MC system, which makes the MC practices substitutes, or the value of one MC practice increases by the simultaneous use of another MC practice in the MC system, which makes the MC practices complements (Milgrom \& Roberts, 1995). The interdependence effects are depicted in Figure 2.

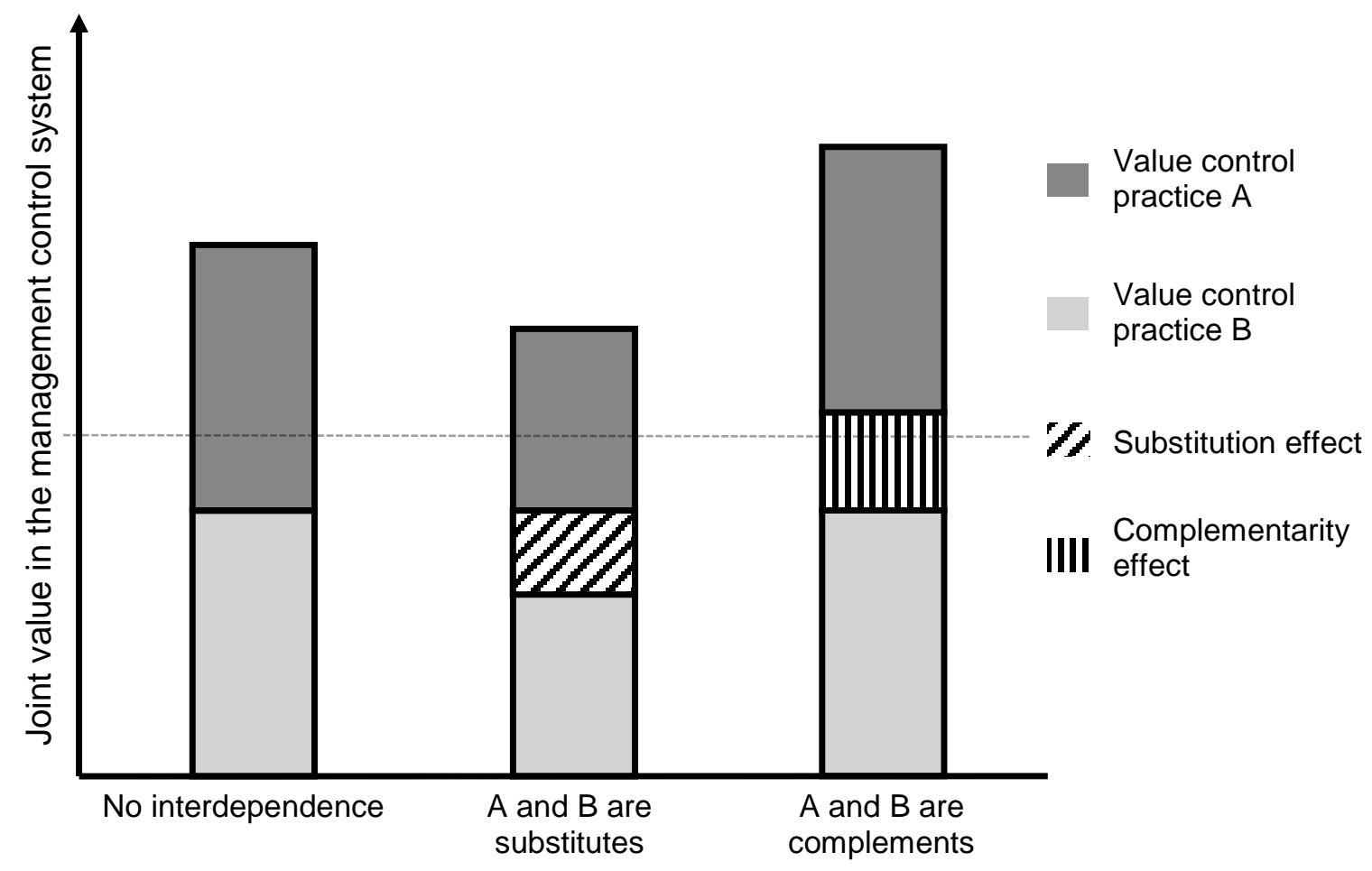

Figure 2: Interdependence effects between management control practices

If two MC practices are substitutes the value of the MC system is less than the cumulative value of the MC practices by themselves. If these MC practices are complements the value of the MC system is more than the cumulative value of the MC practices by themselves. If these MC practices are neither substitutes nor complements the value of the MC system equals the cumulative value of the MC practices by themselves.

Since managers choose among management control practices depending on their net benefit (Simons, 2000), the consideration of substitution and complementarity effects is 


\section{Management control system design}

indispensable when designing effective and efficient MC systems. If these effects are not taken into account the MC system might not be optimal because MC practices set each other off, are redundant or the benefits of complementarity effects are forgone. The following three subsections review the predicted substitution and complementarity effect between behavioral constraints, incentives and employee selection under differing degrees of task uncertainty and output immeasurability that exist within the management accounting literature. Based on these predictions I form the hypotheses which I test.

\subsection{Behavioral Constraints and Incentives}

As outlined above, behavioral constraints are a part of behavior control and incentives are a way to control results. The relationship between behavior control and result control is generally assumed to be of a substitutive nature. Merchant and Van der Stede (2007) state that when controls over behavior are sufficient then there is no need to control results. Similarly Ouchi (1979) and Simons (2000) assume that managers are faced with the choice between relying on either behavior or result control depending on the net benefit of each control type. In addition controlling results is usually less costly than controlling behavior (Simons, 2000; Merchant \& Van der Stede, 2007). Therefore managers are expected to focus on controlling results rather than behavior as long as the context permits this. In addition task uncertainty and output immeasurability, some contextual factors that are assumed to be affecting the relationship are the importance of innovation, time to market requirement and the focus on efficiency and quality (Simons, 2000). To avoid making this research overly complex I do not examine the direct effect of these factors on the interdependence between behavior and result control.

Another view on the interdependence between behavior and result control is that delegation and incentives are complements (Milgrom \& Roberts, 1992). I argue that delegation is in fact the absence of behavioral constraints and that these two control practices can be seen as opposites. Therefore the complementarity between delegation and incentives is equivalent to the substitution between behavioral constraints and incentives. Therefore the predictions by Milgrom and Roberts (1992) are in line with the assumed interdependencies by Ouchi (1979), Simons (2000) and Merchant and Van der Stede (2007). However these relationships are not consistently supported by empirical research. Nagar (2002) finds that incentives do not affect the firms delegation choice, hence also not its choice to constrain behavior. I argue that these inconsistencies are due to the fact the interdependencies of management control practices depend on contextual factors. By examining the interdependency of behavioral constraints and 


\section{Management control system design}

incentives under task uncertainty and output immeasurability I aim at contributing to the clarification of this issue.

The prediction of the interdependency between behavior and result controls under task uncertainty is consistently of substitutive nature. Simons (2000) states that if the cause and effect relationship of what behavior leads to the desired results is not well understood and it is not possible to monitor the behavior, managers have to focus on result controls rather than behavior controls. Merchant and Van der Stede (2007) support this by claiming that result control can lead to effective control even when knowledge about the desirable behavior is lacking. I argue that behavioral constraints as a behavior control and incentives as a result control are particularly suitable to test this interdependency. Correspondingly Milgrom and Roberts (1992) state that difficulty to monitor behavior raises the value of incentives in combination with delegation, hence the substitution effect between behavioral constraints and incentives is larger under task uncertainty. In conclusion, research predicts that ceteris paribus managers rely more on behavior controls under low task uncertainty and more on result control under high task uncertainty. Using behavior controls under low task uncertainty would decrease the value of additional result controls in the management control system and vice versa. I expect the substitution effect therefore to be largest on both ends of the spectrum.

If the substitution effect of behavioral constraints and incentives is moderated by the degree to which tasks are able to be monitored, it is likely that this moderation effect also exists for different degrees of output immeasurability. This was predicted by Ouchi (1979), who assumes that given low task uncertainty, high output immeasurability would lead managers to rely on behavior control rather than result control. For situations where good measures which can be tied to compensation exist (low output immeasurability), Moers (2006) found that incentives based on these measures can complement delegation and therefore substitute behavioral constraints. Similarly as above, it is predicted that under low output immeasurability the use of result controls decreases the marginal value that would be yielded if behavioral constraints were added to the management control system and vice versa. Again I expect this substitution effect to be particularly strong at both extremes.

For my analysis of this substitution effect I use behavioral constraints as behavior control and incentives as result control. Given the predictions reviewed above I expect a significant substitution effect under high output immeasurability/low task uncertainty and under low output immeasurability/high task uncertainty. My hypotheses relating to the interdependence of behavioral constraints and incentives are therefore: 


\section{Management control system design}

H1a: Behavioral constraints and incentives are substitutes under high output immeasurability and low task uncertainty.

H1b: $\quad$ Behavioral constraints and incentives are substitutes under low output immeasurability and high task uncertainty.

\subsection{Incentives and Employee Selection}

Opinions on the rank that personnel/cultural control takes in the control hierarchy differ across the management control literature. Simons (2000) proposes to rely on personnel/cultural control as a last option when controlling behavior and results is not feasible. Merchant and Van der Stede (2007) on the other hand propose to focus on personnel/cultural control first and then extend the management control system with behavior and result controls. While the positive contribution of employee selection to the management control system has been empirically supported (Campbell, 2012), its role within the MC system has not been sufficiently examined.

Theory predicts that managers rely on personnel/cultural control in contexts that are characterized by both high task uncertainty and high output immeasurability (Ouchi, 1979; Simons, 2000). This makes intuitive sense since high task uncertainty/high output immeasurability situations limit the ability to control processes by means of behavior or result control. Specifically related to output immeasurability, Prendergast (2008) assumes that aligning preferences might provide an effective alternative if the alignment of incentives with monetary rewards fails. When looking at task uncertainty Abernethy and Brownell (1997) found that personnel/cultural controls are significantly and positively related to performance in high task uncertainty contexts.

There is to be a consensus about the relevance of personnel/cultural control in high task uncertainty/high output immeasurability situations, but whether these control practices are used to substitute or complement other MC practices within the MC system is not examined. Sole reliance on personnel/cultural controls is generally regarded as being not sufficiently covering the responsibilities of the management control system (Simons, 2000; Merchant \& Van der Stede, 2007), which implies that personnel/cultural control complements result control rather than substituting it. This is supported by Deckop, Mangel, and Circa (1999), who found a low value commitment paired with incentives leading to a disincentive for engaging in organizational citizenship behavior. In other words, ensuring value commitment of employees by devoting more resources to the selection process complements the use of incentives. 


\section{Management control system design}

For my analysis of the interdependence between personnel/cultural control and result control, I use employee selection as a personnel/cultural control practice and incentives for result control. Based on the discussion above I form the hypothesis that:

H2: $\quad$ Employee selection and incentives are complements under high output immeasurability and high task uncertainty.

\subsection{Employee Selection and Behavioral Constraints}

The interdependence of employee selection and behavioral constraints has received less attention than the other two pairs. Recent research of Davila, Foster, and Oyon (2009) proposes that the dynamic capabilities and therefore the long-term survival of large companies could depend on the simultaneous adopting of both organic and mechanic controls, which would imply that the relationship is of complementary nature. An example of organic control is employee selection and behavioral constraints fall in the mechanic control category (Chenhall, 2003). In contrast to this prediction, Abernethy and Brownell (1997) find that under task uncertainty personnel/cultural controls have a positive effect on performance while behavior controls do not affect performance.

In a high task uncertainty/high output immeasurability situation the reliance on personnel/cultural control implies an increased need for specialized and independent employees. Merchant and Van der Stede (2007) state that these individuals react particularly negative to the use of behavior controls. Frustration, demotivation and high employee turnover are reactions that are reported in relation to too tight behavior control. In high task uncertainty/high output immeasurability situations the simultaneous existence of high resource investment in employee selection and tight behavioral constraints reduce the benefit derived from the management control system.

On the other hand in situations in which knowledge about both the desirable behavior and the desirable results exist (low task uncertainty and low output measurability), so behavior controls are very effective, the added value of devoting more than a normal amount of resources to the employee selection process might be relatively small.

Consistent with the other two control practice pairs that I examine, I use employee selection as a personnel/cultural control practice and behavioral constraints for behavior control for my analysis of the interdependence between personnel/cultural control and behavior control. Based on my predictions formed above I form the hypotheses that: 


\section{Management control system design}

H3a Employee selection and behavioral constraints are substitutes under high output immeasurability and high task uncertainty.

H3b Employee selection and behavioral constraints are substitutes under low output immeasurability and low task uncertainty.

\section{Research Method}

\subsection{Sample and Data}

For the statistical analysis of the above formulated hypotheses I use secondary data collected by Grabner (2014) in the course of a study on incentive system design in creativity dependent firms. The data was obtained by sending an online questionnaire to 2,725 managing directors of medium-sized firms in Austria, Germany and Switzerland. Given the intent of her research, Grabner oversampled creativity dependent companies with the majority of firms being randomly selected companies with 50 to 500 employees from all industries. I do not expect this fact to significantly limit the validity of my findings, since I control for both industry factors and creativity dependency. The characteristics of the sample are shown in Table 1 which is adapted from Grabner. The data collection had a response rate of $17.3 \%$ and resulted in 457 usable observations.

In order to test for potential non-response bias Grabner (2014) applied two procedures (Armstrong \& Overton, 1977). Firstly, the responses of early versus late responses were compared using Kruskal-Wallis tests and univariate ANOVAs, which revealed no significant differences. Secondly, Grabner tested for systematic differences between respondents and nonrespondents and found no significant differences, which supports the absence of a significant non-response bias. In addition to her tests for non-response bias, Grabner tackled the problem of common method bias by following the preventive measures proposed by Podsakoff, MacKenzie, Lee, and Podsakoff (2003).

I reperform Harman's one-factor test and the confirmatory factor analysis for the constructs already used in Grabner's research (INCENTIVES², CREATIVITY DEPENDENCY, TASK UNCERTAINTY, OUTPUT IMMEASURABILITY ${ }^{3}$ and ENVIRONMENTAL UNCERTAINTY) and apply the same analysis to the additional constructs that I derived from the

\footnotetext{
${ }^{2}$ INCENTIVES are labelled PBP (performance-based-pay) in Grabner's (2014) research.

${ }^{3}$ Grabner (2014) measures OUTPUT MEASURABILITY rather than OUTPUT IMMEASURABILITY. For the sake of clarity in the direction of my hypotheses I reversed this measure.
} 
Management control system design

data (BEHAVIORAL CONSTRAINTS and SELECTION) in order support the absence of common method bias (Podsakoff \& Organ, 1986).

\begin{tabular}{|c|c|c|c|c|c|}
\hline \multirow[b]{2}{*}{ Industry classification } & \multirow[b]{2}{*}{$\mathbf{N}$} & \multicolumn{2}{|c|}{$\begin{array}{c}\text { TABLE } 1 \\
\text { Sample Description }\end{array}$} & \multirow[b]{2}{*}{$\begin{array}{c}ø \text { Task } \\
\text { Uncertainty }\end{array}$} & \multirow[b]{2}{*}{$\begin{array}{c}\text { ø Output } \\
\text { Immeasurability }\end{array}$} \\
\hline & & $\%$ & $\begin{array}{c}ø \# \\
\text { Employees }\end{array}$ & & \\
\hline Advertising & 44 & $9.6 \%$ & 119 & 4.00 & 3.44 \\
\hline Construction & 14 & $3.1 \%$ & 126 & 3.09 & 2.98 \\
\hline Consultancy & 16 & $3.5 \%$ & 181 & 3.89 & 3.49 \\
\hline Data processing & 9 & $2.0 \%$ & 126 & 4.42 & 3.51 \\
\hline Electricity and water supply & 4 & $0.9 \%$ & 264 & 3.88 & 4.00 \\
\hline Financial intermediation & 2 & $0.4 \%$ & 50 & 4.25 & 2.88 \\
\hline Hotels and restaurants & 8 & $1.8 \%$ & 138 & 2.91 & 4.63 \\
\hline Industrial cleaning & 5 & $1.1 \%$ & 199 & 2.95 & 3.05 \\
\hline $\begin{array}{l}\text { Labor recruitment and provision } \\
\text { of personnel }\end{array}$ & 6 & $1.3 \%$ & 178 & 3.50 & 1.75 \\
\hline $\begin{array}{l}\text { Man. of basic metals and } \\
\text { fabricated metal products }\end{array}$ & 20 & $4.4 \%$ & 159 & 3.40 & 3.26 \\
\hline $\begin{array}{l}\text { Man. of chemicals and chemical } \\
\text { products }\end{array}$ & 8 & $1.8 \%$ & 182 & 3.81 & 3.69 \\
\hline $\begin{array}{l}\text { Man. of electrical and optical } \\
\text { equipment }\end{array}$ & 11 & $2.4 \%$ & 173 & 3.48 & 3.59 \\
\hline $\begin{array}{l}\text { Man. of food products and } \\
\text { beverages }\end{array}$ & 7 & $1.5 \%$ & 150 & 2.68 & 2.96 \\
\hline $\begin{array}{l}\text { Man. of machinery and } \\
\text { equipment N.E.C. }\end{array}$ & 17 & $3.7 \%$ & 185 & 3.97 & 3.24 \\
\hline $\begin{array}{l}\text { Man. of other non-metallic } \\
\text { mineral products }\end{array}$ & 3 & $0.7 \%$ & 96 & 3.08 & 2.25 \\
\hline $\begin{array}{l}\text { Man. of pulp and paper; } \\
\text { publishing and printing }\end{array}$ & 11 & $2.4 \%$ & 172 & 4.02 & 3.68 \\
\hline $\begin{array}{l}\text { Manufacture of rubber and } \\
\text { plastic products }\end{array}$ & 13 & $2.8 \%$ & 138 & 3.75 & 3.56 \\
\hline $\begin{array}{l}\text { Man. of textiles and textile } \\
\text { products }\end{array}$ & 3 & $0.7 \%$ & 161 & 3.17 & 2.08 \\
\hline $\begin{array}{l}\text { Manufacture of transport } \\
\text { equipment }\end{array}$ & 2 & $0.4 \%$ & 137 & 4.50 & 4.38 \\
\hline Manufacturing N.E.C. & 14 & $3.1 \%$ & 144 & 3.55 & 4.05 \\
\hline Other business activities & 6 & $1.3 \%$ & 227 & 3.38 & 3.00 \\
\hline Publishing software & 23 & $5.0 \%$ & 124 & 3.97 & 3.18 \\
\hline Real estate activities & 9 & $2.0 \%$ & 76 & 3.37 & 3.25 \\
\hline Research and development & 59 & $12.9 \%$ & 151 & 4.26 & 3.54 \\
\hline $\begin{array}{l}\text { Software consultancy and } \\
\text { supply }\end{array}$ & 89 & $19.5 \%$ & 134 & 4.12 & 3.32 \\
\hline $\begin{array}{l}\text { Transport, storage and } \\
\text { communication }\end{array}$ & 10 & $2.2 \%$ & 141 & 2.78 & 3.35 \\
\hline Wholesale and retail trade & 44 & $9.6 \%$ & 144 & 3.53 & 3.16 \\
\hline TOTAL & 457 & & & & \\
\hline
\end{tabular}




\section{Management control system design}

\subsection{Variable Measurement}

The observation of conditional interdependencies between control practices is very limited if all control practices that exist within the firm are taken into account. This is due to the different natures of the multiple processes (production, purchasing, HRM etc.). The data collected by Grabner (2014) suits the analysis of interdependencies for two reasons. Firstly, only mediumsized firms that had a single line of business were selected for the sample. This prevents that respondents report unrelated control practices of different product or service lines.

\begin{tabular}{|c|c|}
\hline \multicolumn{2}{|l|}{$\begin{array}{c}\text { TABLE 2 } \\
\text { Construct Validity }\end{array}$} \\
\hline Behavioral Constraints & Factor $(0.61)$ \\
\hline Employees' discretion to schedule own work $(\mathrm{R})$ & 0.727 \\
\hline Employees' discretion to make decisions $(\mathrm{R})$ & 0.848 \\
\hline Employees' dependency on supervisor's approval for most decision & 0.804 \\
\hline Employees' dependency on supervisor's approval for matters of minor importance & 0.735 \\
\hline Incentives & Factor $(0.61)$ \\
\hline Employees' individual performance determines remuneration & 0.834 \\
\hline Differences in remuneration are due to performance differences & 0.801 \\
\hline Employee rewards are based on performance & 0.711 \\
\hline Selection & Factor $(0.61)$ \\
\hline Emphasis placed on the recruiting process & 0.851 \\
\hline Investment of resources into the recruiting process & 0.832 \\
\hline Pride in hiring the best employees & 0.699 \\
\hline Presence of multi-stage application process & 0.737 \\
\hline Task Uncertainty & Factor $(0.50)$ \\
\hline Extent to which effective and ineffective employees can be distinguished (R) & 0.668 \\
\hline Extent to which resource investment of employees is assessable $(R)$ & 0.749 \\
\hline Predictability of paths of actions employees have to take & 0.724 \\
\hline Predictability of employees' success & 0.672 \\
\hline Output Immeasurability & Factor $(0.66)$ \\
\hline Clear definition of performance requirements $(\mathrm{R})$ & 0.842 \\
\hline Objective data available for measuring individual performance $(R)$ & 0.878 \\
\hline Precision of performance indicators $(R)$ & 0.816 \\
\hline Unambiguous objectives for employees cannot be defined & 0.691 \\
\hline Creativity Dependency & Factor $(0.83)$ \\
\hline Employee creativity is the primary source of value creation & 0.887 \\
\hline Selling creative ideas is the largest revenue source & 0.870 \\
\hline Commercial success of products depends primarily on employees' creativity & 0.925 \\
\hline Competitive edge depends on employees' creativity & 0.935 \\
\hline Creativity is the main input factor for products or services & 0.923 \\
\hline Environmental Uncertainty & Factor $(0.42)$ \\
\hline Uncertainty of customers' purchasing behavior & 0.649 \\
\hline Uncertainty of technical development & 0.676 \\
\hline Uncertainty of suppliers' strategies and behaviors & 0.601 \\
\hline Uncertainty of competitors' strategies and behaviors & 0.639 \\
\hline Uncertainty of the labor market & 0.662 \\
\hline
\end{tabular}




\section{Management control system design}

Secondly, the questionnaire explicitly states that all questions are aimed at the core process of producing products or rendering services, excluding all supporting processes. This reduces bias caused by control practices that are put in place for processes other than the core process.

\subsection{Control Procedure Variables}

Given the secondary nature of the data, I rely on the construct measurement used by Grabner (2014). Grabner measures the degree to which the three management control practices (BEHAVIORAL CONSTRAINTS, INCENTIVES and EMPLOYEE SELECTION) are employed on a 7-point Likert scale. The content of the survey questions is shown in Table 2. The three item construct for INCENTIVES was adapted from Snell (1992) and Nagar (2002) and measures the extent to which the remuneration of employees is based on performance. I use confirmatory factor analysis and examine the respective Cronbach's alphas to support the validity of the constructs. The proxies for the constructs are derived by computing the average of the respective items. The factor loading of the items for each construct are reported in Table 2.

In Table 3, Panel A reports the descriptive statistics of the responses for the proxies and shows that nearly all constructs encompass the values from the minimum 1 to the maximum 7 . Panel B shows the multi-trait matrix with the Cronbach's alpha of each construct reported in the diagonal of the matrix and the bivariate correlations below. The panel shows that all bivariate correlations are smaller than the Cronbach's alpha of their respective two proxies, which supports the validity of the constructs (Churchill, 1979).

\section{TABLE 3}

Panel A: Descriptive statistics for survey constructs $(\mathrm{N}=457)$

\begin{tabular}{lcccccccc}
\hline & \# Items & Mean & Std & Min & 1st Q. & Med & 3rd Q. & Max \\
\hline Behavioral constraints & 4 & 2.64 & 1.05 & 1 & 2.00 & 2.50 & 3.25 & 6.25 \\
Incentives & 3 & 5.25 & 1.17 & 1 & 4.67 & 5.33 & 6.00 & 7 \\
Selection & 4 & 4.89 & 1.18 & 1 & 4.00 & 5.00 & 5.75 & 7 \\
Task uncertainty & 4 & 3.81 & 1.13 & 1 & 3.00 & 3.75 & 4.50 & 7 \\
Output immeasurability & 4 & 3.37 & 1.34 & 1 & 2.25 & 3.25 & 4.25 & 7 \\
Creativity dependency & 5 & 4.18 & 1.68 & 1 & 2.80 & 4.20 & 5.60 & 7 \\
Environmental uncertainty & 5 & 4.39 & 0.95 & 1 & 3.90 & 4.40 & 5.00 & 7 \\
\hline
\end{tabular}


Management control system design

Panel B: Multi-trait matrix

\begin{tabular}{llllllll}
\hline & 1 & 2 & 3 & 4 & 5 & 6 & 7 \\
\hline Behavioral constraints & $\mathbf{0 . 7 8}$ & & & & & & \\
Incentives & $-0.156^{* *}$ & $\mathbf{0 . 6 9}$ & & & & & \\
Selection & $-0.234^{* *}$ & $0.256^{* *}$ & $\mathbf{0 . 7 8}$ & & & & \\
Task uncertainty & $-0.151^{* *}$ & -0.088 & $0.158^{* *}$ & $\mathbf{0 . 6 6}$ & & & \\
Output immeasurability & 0.058 & $-0.309^{* *}$ & $-0.256^{* *}$ & $0.268^{* *}$ & $\mathbf{0 . 8 2}$ & & \\
Creativity dependency & $-0.266^{* *}$ & $0.181^{* *}$ & $0.223^{* *}$ & $0.186^{* *}$ & 0.031 & $\mathbf{0 . 9 5}$ & \\
Environmental uncertainty & 0.075 & $0.182^{* *}$ & 0.080 & $-0.097^{*}$ & $-0.254^{* *}$ & 0.047 & $\mathbf{0 . 6 5}$ \\
\hline${ }^{*} \mathrm{p}<0.05$ and **$p<0.01$ (two-tailed test) & & & & & & \\
The diagonal of Panel B shows the Cronbach's Alphas of the constructs. & & & \\
\hline
\end{tabular}

\subsection{Moderating and Control Variables}

As discussed in Section II I examine the conditional correlations under high and low TASK UNCERTAINTY and OUTPUT IMMEASURABILITY. Both constructs are measured by four items that are adapted from Snell (1992), who used these variables in a very similar research context. Since they are affecting management control practice choices I also control for these variables when performing the regression. Another variable that is found to affect management control system design is CREATIVITY DENPENDENCY (Grabner, 2014). Given the absence of a measurement construct for this variable, Grabner developed a five-item construct which she supported by conducting several analyses. Furthermore the MC system design is affected by contextual variables, such as the external environment and size of the firm. ENVIRONMENTAL uncertainty is measure with a five-item construct which is adapted by Moers (2006). Industry effects are controlled for by adding dummies for whether the company belongs to the service industry or operates in the scientific research field (SERVICE and RESEARCH\&DEVELOPMENT). Finally, FIRM SIZE is measured by the natural logarithm of the total number of employees.

\section{Results}

Simply examining the correlation between the management control practices does not provide information about interdependency since the correlation is biased by joint determinants (Grabner \& Moers, 2013). However the direction of the interdependence relationship follows the direction of the conditional covariance (Arora \& Gambardella, 1990). Therefore, assuming that managers 


\section{Management control system design}

take interdependencies into account when designing management control systems, I estimate the demand functions for the management control practices and correlate the residuals.

BEHAVIORAL CONSTRAINTS =

$\beta_{0}+\beta_{1}$ TASK UNCERTAINTY $+\beta_{2}$ OUTPUT IMMEASURABILITY $+\beta_{3}$ CREATIVITY DEPENDENCY $+\beta_{4}$ ENVIRONMENTAL UNCERTAINTY $+\beta_{5}$ RESEARCH\&DEVELOPMENT + $\beta_{6}$ SERVICE $+\beta_{7}$ FIRM SIZE $+\varepsilon$

INCENTIVES $=$

$\beta_{0}+\beta_{1}$ TASK UNCERTAINTY $+\beta_{2}$ OUTPUT IMMEASURABILITY $+\beta_{3}$ CREATIVITY DEPENDENCY $+\beta_{4}$ ENVIRONMENTAL UNCERTAINTY $+\beta_{5}$ RESEARCH\&DEVELOPMENT $+\beta_{6}$ SERVICE $+\beta_{7}$ FIRM SIZE $+\varepsilon$

EMPLOYEE SELECTION =

$\beta_{0}+\beta_{1}$ TASK UNCERTAINTY $+\beta_{2}$ OUTPUT IMMEASURABILITY $+\beta_{3}+$ CREATIVITY DEPENDENCY + $\beta 4$ ENVIRONMENTAL UNCERTAINTY + $\beta_{5}$ RESEARCH\&DEVELOPMENT + $\beta_{6}$ SERVICE $+\beta_{7}$ FIRM SIZE $+\varepsilon$

In addition to providing the predicted values needed to compute the residuals, the regression reveals insights about the determinants for the use of the three management control practices. TASK UNCERTAINTY significantly decreases the extent to which BEHAVIORAL CONSTRAINTS are employed ( $\beta_{1} \approx-0.109, p<0.05$; two-tailed), while the employment of EMPLOYEE SELECTION significantly increases with TASK UNCERTAINTY $\left(\beta_{1} \approx 0.211, p<\right.$ 0.01; two-tailed). This is intuitive since TASK UNCERTAINTY decreases the applicability of BEHAVIORAL CONSTRAINTS and for tasks that are characterized by high TASK UNCERTAINTY more specialized personnel might be needed. OUTPUT IMMEASURABILITY on the other hand significantly increases the extent to which BEHAVIORAL CONSTRAINTS are employed ( $\beta_{2} \approx 0.090, p<0.05$; two-tailed), while the focus on EMPLOYEE SELECTION as a control practice decreases with OUTPUT IMMEASURABILITY ( $\beta_{1} \approx-0.259, p<0.01$; two-tailed). Furthermore the degree to which INCENTIVES are employed also decreases as outputs become less measurable $\left(\beta_{2} \approx-0.243, p<0.01\right.$; two-tailed). Again the direction of the relationships are as expected which supports the validity of the constructs. CREATIVITY DEPENDENCY significantly decreases the use of BEHAVIORAL CONSTRAINTS $\left(\beta_{3} \approx-0.155, p\right.$ $<0.01$; two-tailed), while it increases the use of INCENTIVES $\left(\beta_{3} \approx 0.137, p<0.01\right.$; two-tailed) and EMPLOYEE SELECTION $\left(\beta_{3} \approx 0.138, p<0.01\right.$; two-tailed). 


\begin{tabular}{|c|c|c|c|}
\hline \multicolumn{4}{|c|}{$\begin{array}{c}\text { TABLE } 4 \\
\text { Regression Analysis }\end{array}$} \\
\hline & $\begin{array}{l}\text { Behavioral } \\
\text { Constraints }\end{array}$ & Incentives & $\begin{array}{l}\text { Employee } \\
\text { Selection }\end{array}$ \\
\hline \multirow[t]{2}{*}{ Intercept } & $3.374^{* * *}$ & $4.772^{\star \star \star}$ & $2.527^{\star \star \star}$ \\
\hline & $(0.475)$ & $(0.519)$ & $(0.508)$ \\
\hline \multirow[t]{2}{*}{ Task uncertainty } & $-0.109^{\star *}$ & -0.025 & $0.211^{* * *}$ \\
\hline & $(0.044)$ & $(0.048)$ & $(0.047)$ \\
\hline \multirow[t]{2}{*}{ Output immeasurability } & $0.090^{\star *}$ & $-0.243^{\star \star \star}$ & $-0.259^{* * *}$ \\
\hline & $(0.37)$ & $(0.041)$ & $(0.040)$ \\
\hline \multirow[t]{2}{*}{ Creativity dependency } & $-0.155^{\star \star \star}$ & $0.137^{* \star *}$ & $0.138^{* * *}$ \\
\hline & $(0.028)$ & $(0.031)$ & $(0.030)$ \\
\hline \multirow[t]{2}{*}{ Environmental uncertainty } & $0.111^{* *}$ & $0.107^{*}$ & 0.030 \\
\hline & $(0.052)$ & $(0.056)$ & $(0.055)$ \\
\hline \multirow[t]{2}{*}{ Research \& development } & -0.269 & $-0.339^{*}$ & 0.261 \\
\hline & $(0.165)$ & $(0.180)$ & $(0.176)$ \\
\hline \multirow[t]{2}{*}{ Service } & $-0.308^{\star \star *}$ & 0.104 & $0.328^{* * *}$ \\
\hline & $(0.113)$ & $(0.124)$ & $(0.121)$ \\
\hline \multirow[t]{2}{*}{ Firm size } & $-0,048$ & 0.068 & $0.304^{* * *}$ \\
\hline & $-0,062$ & $(0.068)$ & $(0.066)$ \\
\hline $\mathrm{R}^{2}$ & 0.10 & 0.15 & 0.19 \\
\hline $\mathrm{F}$ & $8.460 * \star \star$ & $12.109^{\star \star \star}$ & $16.366^{\star \star \star}$ \\
\hline$n$ & 457 & 457 & 457 \\
\hline
\end{tabular}

In addition, the regressions show support for an increased reliance on BEHAVIORAL CONSTRAINTS $\left(\beta_{4} \approx 0.111, p<0.05\right.$; two-tailed) under higher ENVIRONMENTAL UNCERTAINTY and some support for an increased reliance on INCENTIVES $\left(\beta_{4} \approx 0.107, p<\right.$ 0.1; two-tailed) under higher ENVIRONMENTAL UNCERTAINTY. A possible explanation for this would be that in situations characterized by ENVIRONMENTAL UNCERTAINTY management relies on more direct forms of control in order to mitigate the increased risk. The regression shows that industrial factors also affect the management control practice choice. Some support is found that managers rely less on INCENTIVES in research and development intensive companies $\left(\beta_{5} \approx-0.339, p<0.1\right.$; two-tailed). In service industries firms rely significantly less on BEHAVIORAL CONSTRAINTS $\left(\beta_{6} \approx-0.308, p<0.01\right.$; two-tailed) and place more emphasis on EMPLOYEE SELECTION $\left(\beta_{6} \approx 0.328, p<0.01\right.$; two-tailed). FIRM SIZE only significantly affects 


\section{Management control system design}

EMPLOYEE SELECTION and the relationship is positive $\left(\beta_{7} \approx 0.304, p<0.01\right.$; two-tailed). A possible explanation for this is that larger firms have more resources available and also hire more employees, which justifies a larger resource investment in the recruitment process.

In order to examine the conditional interdependencies between the three management control practices I create dummies for high TASK UNCERTAINTY and high OUTPUT IMMEASURABILITY by splitting the variables at the median. Based on these two dummies I derive my four subgroups; high/high, high/low, low/high and low/low. For each of the subgroups I examine the bivariate correlation between the respective residuals.

The hypothesized interdependence effects between BEHAVIORAL CONSTRAINTS and INCENTIVES are that they are substitutes under high OUTPUT IMMEASURABILITY and low TASK UNCERTAINTY (H1a) and under low OUTPUT IMMEASURABILITY and high TASK UNCERTAINTY (H1b). Panel A of Table 5 shows the conditional correlations between the two management control practices. The lower left quadrant reveals that $\mathrm{H} 1 \mathrm{a}$ is supported at a $1 \%$ significance level. In situations where knowledge about the desired course of action exists, these actions can be monitored but knowledge about the optimal result and the ability to measure results is limited, BEHAVIORAL CONSTRAINTS and INCENTIVES act as substitutes.

\begin{tabular}{|c|c|c|c|}
\hline \multicolumn{2}{|c|}{ Conditional Correlations } & & \\
\hline \multicolumn{4}{|c|}{ Panel A: Behavioral Constraints and Incentives } \\
\hline \multirow{4}{*}{$\begin{array}{c}\text { Task } \\
\text { Uncertainty }\end{array}$} & & \multicolumn{2}{|c|}{ Output Immeasurability } \\
\hline & & High & Low \\
\hline & High & $\begin{array}{c}-.109 \\
N=123\end{array}$ & $\begin{array}{c}.015 \\
N=96\end{array}$ \\
\hline & Low & $\begin{array}{c}-.344^{* * *} \\
\mathrm{~N}=94\end{array}$ & $\begin{array}{c}.000 \\
N=144\end{array}$ \\
\hline
\end{tabular}

Hence, the value of their joint use decreases in this context. The upper right quadrant however shows that $\mathrm{H} 1 \mathrm{~b}$ is not supported. In fact there appears to be no significant interdependence at all in any other combination of TASK UNCERTAINTY and OUTPUT IMMEASURABILITY than the one in the lower left quadrant. This means that in these contexts BEHAVIORAL CONTRAINTS and INCENTIVES seem to be not interdependent, so their joint 


\section{Management control system design}

value in the management control system is not affected by the coexistence of the other management control practice.

The hypothesized interdependence relationship of EMPLOYEE SELECTION and INCENTIVES is that they are complements in situations characterized by both high OUTPUT IMMEASURABILITY and TASK UNCERTAINTY (H2). The conditional correlations between EMPLOYEE SELECTION and INCENTIVES are shown in Panel B of Table 5.

\section{TABLE 5}

\section{Conditional Correlations}

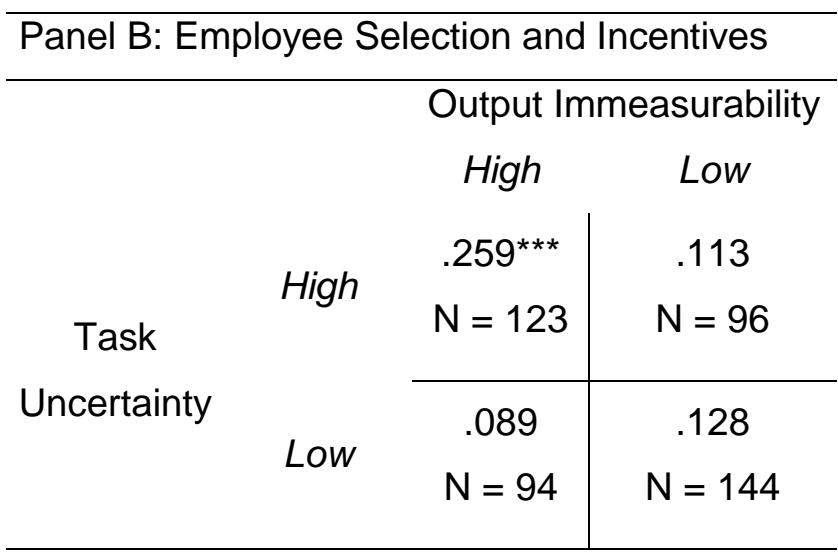

The upper left quadrant shows that $\mathrm{H} 2$ is supported. Rather than substituting INCENTIVES with EMPLOYEE SELECTION in high OUTPUT IMMEASURABILITY/high TASK UNCERTAINTY contexts, managers specifically employ these measures together when designing management control systems.

Using both EMPLOYEE SELECTION and INCENTIVES simultaneously seems to lead to a complementation effect; hence the joint value of the MC practices when employed together is larger than their cumulative value if they were not employed together. In other contexts however there appears to be no significant interdependence effect. This might be due to the fact that in a high OUTPUT IMMEASURABILITY/high TASK UNCERTAINTY context, both MC practices by themselves do not provide a sufficient degree of control, so they should be employed together. In other contexts however a sufficient degree of control might be achieved by relying either on one MC practice or on both

Lastly, the hypothesized interdependence relationships between EMPLOYEE SELECTION and BEHAVIORAL CONSTRAINTS are that they are substitutes in a high OUTPUT IMMEASURABILITY/high TASK UNCERTAINTY (H3a) and in a low OUTPUT 


\section{Management control system design}

IMMEASURABILITY/low TASK UNCERTAINTY (H3b) context. The upper left quadrant of Panel $\mathrm{C}$ in Table 5 shows support for $\mathrm{H} 3 \mathrm{a}$.

In a high OUTPUT IMMEASURABLITY/high TASK UNCERTAINTY context EMPLOYEE SELECTION and BEHAVIORAL CONSTRAINTS appear to act as substitutes. The high degree of uncertainty related to this context makes BEHAVIORAL CONSTRAINTS by themselves insufficient to provide reasonable control. In fact, as described in Section II, the value of BEHAVIORAL CONSTRAINTS decreases for specialized and more independent employees, which are sought for with a high resource investment in EMPLOYEE SELECTION.

\begin{tabular}{|c|c|c|}
\hline \multicolumn{3}{|c|}{ TABEL 5} \\
\hline \multicolumn{3}{|c|}{ Conditional Correlations } \\
\hline \multicolumn{3}{|c|}{ Panel C: Employee Selection and Behavioral Constraints } \\
\hline & \multicolumn{2}{|c|}{ Output Immeasurability } \\
\hline & High & Low \\
\hline High & $\begin{array}{l}-.189^{\star *} \\
N=123\end{array}$ & $\begin{array}{c}.054 \\
N=96\end{array}$ \\
\hline \multicolumn{3}{|l|}{ Task Uncertainty } \\
\hline Low & $\begin{array}{c}-.069 \\
N=94\end{array}$ & $\begin{array}{l}-.273^{\star \star *} \\
\mathrm{~N}=144\end{array}$ \\
\hline
\end{tabular}

The lower right quadrant of Panel $\mathrm{C}$ in Table 5 shows that also $\mathrm{H} 3 \mathrm{~b}$ is supported, so EMPLOYEE SELECTION and BEHAVIORAL CONSTRAINTS also appear to be substitutes under low OUTPUT IMMEASURABILITY and low TASK UNCERTAINTY. A possible explanation for this is that this context is relatively easy to control. The additional value of investing more than a normal amount of resources in EMPLOYEE SELECTION, when relying on BEHAVIORAL CONSTRAINTS provides sufficient control, is likely to be low. Therefore, in an effort to keep the costs as low as possible, managers seem to not rely on EMPLOYEE SELECTION and BEHAVIORAL CONSTRAINTS simultaneously in this context. 


\section{Management control system design}

\section{Conclusion}

Interdependence between management control practices is a topic that has been subject to many assumptions but little empirical findings corroborate these predictions. By examining interdependence effects under differing levels of task uncertainty and output immeasurability after controlling for joint determinants my findings support some of these predictions and contradict others.

Specifically I find that in situations characterized by low task uncertainty and low output immeasurability employee selection and behavioral constraints act as substitutes. In a low task uncertainty/high output immeasurability context behavioral constraints and employee selection appear to act as substitutes. In a high task uncertainty/low output immeasurability setting there appear to be no significant interdependence effects between behavioral constraints, incentives and employee selection. Lastly, given a high task uncertainty/high output immeasurability background I find that incentives and employee selection act as complements and employee selection and behavioral constraints are substitutes.

My findings contribute to the understanding of management control system design. In addition to contextual factors, the composition of the management control system depends on the internal consistency of the management control practices. I also show that management control practices are subject to interdependence effects in some contexts while they do not affect each other in other contexts. Managers therefore have to carefully design management control systems in order to meet the external demands of the control problem and achieve internal consistency at the same time.

\section{Limitations \& Future Research}

Management control systems are dependent on cultural factors (Harrison \& McKinnon, 1999). Since the sample is based exclusively on German, Austrian and Swiss companies, one limitation of my study is that my findings might be not representative for other cultural settings. Future research could examine the interdependence relationships with samples from other countries to analyze how these interdependencies differ in other cultures.

Also I examine only one management control practice of each type of control (personnel/cultural, behavior and result control). Interdependencies are likely to differ when other management control practices are chosen. The general research field of management control system design is therefore far from being explored. Future research can examine the interdependencies of other management control practices such as culture control, different types of budgets, performance targets, performance evaluations or pre-action reviews. 


\section{Management control system design}

Task uncertainty and output immeasurability are likely to be not the only factors that moderate the interdependence relationship between control practices. Future research could also examine interdependencies under different management control problems. Management control problems can be (1) the lack of direction, (2) motivational problems and (3) personal limitations (Merchant \& Van der Stede, 2007, p. 8).

Furthermore there are limitations that come with my analysis. Even though I controlled for joint determinants in my analysis it is still possible that the correlations between the residuals are biased by unknown joint determinants. Naturally, regressions with a larger predictive power decrease this risk further. Additionally, in order to interpret the interdependencies I am making the assumption that managers make benefit maximizing management control system design choices. If we assume that this condition does not hold, my findings might not represent the real complementation and substitution effects. 


\section{Management control system design}

\section{References}

Abernethy, M. A., \& Brownell, P. (1997). Management control systems in research and development organizations: The role of accounting, behavior and personnel controls. Accounting, Organizations and Society, 22(3/4), 233-248.

Anthony, R. N. (1988). The Management Control Function. Boston, MA: The Harvard Business School Press.

Armstrong, J. S., \& Overton, T. S. (1977). Estimating nonresponse bias in mail surveys. Journal of Marketing Research, 14, 396-402.

Arora, A., \& Gambardella, A. (1990). Complementarity and External Linkages: The Strategies of the Large Firms in Biotechnology. The Journal of Industrial Economics, 38(4), 361-379.

Baiman, S. (1990). Agency research in managerial accounting: A second look. Accounting, Organizations and Society, 15(4), 341-371.

Campbell, D. (2012). Employee Selection as a Control System. Journal of Accounting Research, 50(4), 931-966.

Chenhall, R. H. (2003). Management control systems design within its organizational context: findings from contingency-based research and directions for the future. Accounting, Organizations and Society, 28(2/3), 127-168.

Churchill, G. A. (1979). A Paradigm for Developing Better Measures of Marketing Constructs. Journal of Marketing Research, 16(1), 64-73.

Davila, A., Foster, G., \& Oyon, D. (2009). Accounting and Control, Entrepreneurship and Innovation: Venturing into New Research Opportunities. European Accounting Review, 18(2), 281-311.

Deckop, J. R., Mangel, R., \& Cirka, C. C. (1999). Getting More Than You Pay For: Organizational Citizenship Behavior and Pay-For-Performance Plans. Academy of Management Journal, 42(4), 420-428.

Grabner, I. (2014). Incentive design in creativity-dependent firms. The Accounting Review, forthcoming.

Grabner, I., \& Moers, F. (2013). Management control as a system or as a package? Conceptual and empirical issues. Accounting, Organizations and Society, 38, 407-419.

Harrison, G. L., \& McKinnon, J. L. (1999). Cross-cultural research in management control systems. Accounting, Organizations and Society, 24(5/6), 483-506.

Malmi, T., \& Brown, D. A. (2008). Management control systems as a package - Opportunities, challenges and research directions. Management Accounting Research, 19(4), 287-300.

Merchant, K. A., \& Van der Stede, W. A. (2007). Management Control Systems: Performance Measurement, Evaluation and Incentives (2nd ed.). Harlow: Financial Times/Prentice Hall.

Milgrom, P., \& Roberts, J. (1992). Economics, Organization and Management. Englewood Cliffs, NJ: Prentice-Hall, Inc.

Milgrom, P., \& Roberts, J. (1995). Complementarities and fit: Strategy, structure, and organizational change in manufacturing. Journal of Accounting and Economics, 19(2/3), 179208.

Moers, F. (2006). Performance Measure Properties and Delegation. The Accounting Review, 81(4), 897-924.

Nagar, V. (2002). Delegation and Incentive Compensation. The Accounting Review, 77(2), 379395. 


\section{Management control system design}

Ouchi, W. G. (1979). A Conceptual Framework for the Design of Organizational Control Mechanisms. Management Science, 25(9), 833-848.

Podsakoff, P. M., \& Organ, D. W. (1986). Self-reports in organizational research: Problems and prospects. Journal of Management, 12(4), 531-544.

Podsakoff, P. M., MacKenzie, S. B., Lee, J. Y., \& Podsakoff, N. P. (2003). Common method biases in behavioral research: A critical review of the literature and recommended remedies. Journal of Applied Psychology, 88(5), 879-903.

Prendergast, C. (2008). Intrinsic Motivation and Incentives. The American Economic Review, 98(2), 201-205.

Simons, R. (2000). Performance Measurement \& Control Systems for Implementing Strategy. Upper Saddle River, N.J: Prentice Hall.

Snell, S. A. (1992). Control theory in strategic human resource management: The mediating effect of administrative information. Academy of Management Journal, 35(2), 292-327.

Wright, P. M., Dunford, B. B., \& Snell, S. A. (2001). Human resources and the resource based view of the firm. Journal of Management, 27(6), 701-721. 